$K_{m}$ values towards a given substrate and inactivation by heat, as well as in electrophoretic mobility (Wilkinson, Cooke, Elliott \& Plummer, 1961; Plagemann, Gregory \& Wróblewski, 1960). These lactatedehydrogenase isoenzymes thus appear to be distinct proteins, with closely similar, but not identical, enzyme activities, and probably occur as such in vivo. Further, homologous isoenzyme zones from different tissues appear to resemble each other. The findings for the alkaline-phosphatase fractions do not appear, therefore, to parallel those for lactate dehydrogenase. In the present study the only difference found between the phosphatase fractions from a single tissue was in electrophoretic mobility, and homologous enzyme bands from different tissues, e.g. the main zones from liver and bone, were dissimilar in properties.

\section{SUMMARY}

1. Starch-gel electrophoresis of concentrated butan-1-ol extracts of human bone, liver, kidney and small intestine reveals a number of active alkaline-phosphatase fractions in each.

2. The apparent $K_{m}$ values (substrate, $\beta$ naphthyl phosphate) of the individual enzyme bands from these tissues have been determined. Other properties of the bands, namely $\mathrm{pH}$ optimum, activation by $\mathrm{Mg}^{2+}$ ions and inactivation by heating at $55^{\circ}$ and $\mathrm{pH} 7$, have also been studied.
3. The phosphatase fractions from a given organ are similar in these properties and in $K_{m}$ values, although there are some differences between phosphatases from different tissues.

4. The significance of these findings is discussed.

\section{REFERENCES}

Ahmed, Z. \& King, E. J. (1960). Biochim. biophys. Acta, 40, 320.

Boyer, S. H. (1961). Science, 134, 1002.

Delory, G. E. \& King, E. J. (1945). Biochem. J. 39, 245.

Dixon, M. \& Webb, E. C. (1958). Enzymes, p. 630. London: Longmans, Green and Co. Ltd.

King, E. J. \& Armstrong, A. R. (1934). Canad. med. Ass. J. 31, 376.

Lineweaver, H. \& Burk, D. (1934). J. Amer. chem. Soc. 56, 658.

Morton, R. K. (1950). Nature, Lond., 166, 1092.

Moss, D. W. (1960). Biochem. J. 76, 32 P.

Moss, D. W. (1962). Nature, Lond., 193, 981.

Moss, D. W., Campbell, D. M., Anagnostou-Kakaras, E. \& King, E. J. (1961). Biochem. J. 81, 441.

Moss, D. W. \& King, E. J. (1962). Biochem. J. 82, 19 P.

Motzok, I. (1959). Biochem. J. 72, 169.

Plagemann, P. G. W., Gregory, K. F. \& Wróblewski, F. (1960). J. biol. Chem. 325, 2288.

Poulik, M. D. (1957). Nature, Lond., 180, 1477.

Smithies, O. (1955). Biochem. J. 61, 629.

Wilkinson, J. H., Cooke, K. B., Elliott, B. A. \& Plummer, D. T. (1961). Biochem. J. 80, 29 P.

Wróblewski, F. (1961). Ann. N.Y. Acad. Sci. 84, 655.

Biochem. J. (1962) 84, 195

\title{
The Oxidation of Steroids with tert.-Butyl Ghromate
}

\author{
By E. MENINI AND J. K. NORYMBERSKI \\ Chemical Pathology of Steroids Research Unit (Medical Research Council), Jessop Hospital \\ for Women, Sheffield 3
}

(Received 29 January 1962)

The oxidation of steroidal secondary alcohols to ketones is readily effected by a variety of agents, often with almost quantitative yields. The relevant literature (see Fieser \& Fieser, 1959) largely concerns preparative experiments necessitating the use of only a slight excess of the oxidant. The application of this conversion to the analysis of complex mixtures of steroids seems promising, since in general it is easier to detect and measure very small quantities of ketones than of the corresponding alcohols. To perform the reaction effectively on an analytical sample of unknown composition an oxidant is required which, even when used in large excess, acts in a predictable manner, so that measurement or identification of the reaction products will give information about the amounts or identities of the compounds under investigation.

Oppenauer \& Oberrauch (1949) introduced tert.-butyl chromate as an oxidizing agent and employed it in a mixture of 2-methylpropan-2-ol and an inert non-polar organic solvent, in the non-polar solvent alone and in a mixture of the solvent and acetic acid. They observed that increased acidity made the oxidation more vigorous and less selective. We hoped to increase the selectivity of the reagent by performing the oxidation in the presence of an organic base. The chromic anhydride-pyridine complex (Poos, Arth, 
Beyler \& Sarett, 1953) seemed less suited to our purpose since this reagent, prepared and used as a suspension in pyridine, is less easy to handle in small quantities. We now report a series of experiments intended to assess the analytical value of tert.-butyl chromate.

\section{EXPERIMENTAL}

Paper chromatography. The systems $\mathrm{B}_{3}$ [light petroleumbenzene-methanol-water $(67: 33: 80: 20$, by vol.)] (Bush, $1952)$ and $E_{4}[2,2,4$-trimethylpentane-2-methylpropan-2ol-methanol-water $(20: 9: 9: 2$, by vol.)] (Eberlein \& Bongiovanni, 1955) were used on Whatman no. 2 paper by the descending technique at $22^{\circ}$. With the $\mathrm{B}_{3}$ system, movement of solvent was slowed down by tapering the portion of paper immersed in the mobile phase. Chromatographic fractions were detected by the following tests: $(a)$ inspection in ultraviolet light of approximately $250 \mathrm{~m} \mu$; (b) alkali test: treatment with sodium hydroxide [ $2 \mathrm{~N}$ in $25 \%(v / v)$ ethanol] followed by inspection in white light and in ultraviolet light of approximately $360 \mathrm{~m} \mu$, the latter being repeated after the paper became dry at room temperature; (c) Zimmermann test: treatment with a mixture (1:1, $\nabla / v)$ of an ethanolic solution of $m$-dinitrobenzene $(0.5 \%$, w/v) and aq. potassium hydroxide $(5 \mathrm{~N})$ followed by heating over a hot-plate or in an oven at $60^{\circ}$ and frequent inspection. Reagents were applied to the paper by a trough and roller.

Chromatography on alumina. Alumina (Peter Spence, grade H) was kept overnight in ethyl acetate. It was then washed with de-ionized water until neutral and reactivated by heating at $200^{\circ}$ for $3 \mathrm{hr}$. It was used in 50- to 100 -fold excess over the material chromatographed. The gradient elution technique of Appleby \& Norymberski (1955) was employed, the composition of the eluent being gradually varied from benzene or benzene-light petroleum (b.p. $\left.60-80^{\circ}\right)(1: 1, v / v)$ to benzene-thyl acetate $(1: 1, v / v)$.

tert.-Butyl chromate reagent. The method of Oppenauer \& Oberrauch (1949) was slightly modified. Chromic anhydride (5 g.) was added in small portions to a stirred and chilled mixture of 2-methylpropan-2-ol (10 ml.) and carbon tetrachloride $(10 \mathrm{ml}$.). The mixture was diluted with carbon tetrachloride $(65 \mathrm{ml}$.) and filtered through a layer of anhydrous sodium sulphate on a sintered-glass funnel, and the filter was washed with the solvent $(10 \mathrm{ml}$.). The solution was stored at $4^{\circ}$ over anhydrous sodium sulphate.

General oxidation procedure. (i) Analytical oxidations. A solution of the steroid $(0.5 \mathrm{mg}$. or less $)$ in pyridine $(0.1 \mathrm{ml}$.) and the tert.-butyl chromate reagent $(0.1 \mathrm{ml}$.) were mixed and left overnight at room temperature. A freshly prepared saturated solution of citric acid in ethanol $(0 \cdot 2 \mathrm{ml}$. $)$ was added and the mixture shaken for $15 \mathrm{~min}$. N-Sulphuric acid $(1 \mathrm{ml}$.$) and ethylene dichloride (3.0 \mathrm{ml}$.) were then added and the mixture was shaken for $15 \mathrm{~min}$. The top layer was removed with suction and the organic phase was washed successively with $1 \mathrm{ml}$. each of water, $10 \%(\mathrm{w} / \mathrm{v})$ sodium metabisulphite (sodium disulphite), N-sodium hydroxide and water (the alkali wash was omitted when alkali-extractable products were expected). The washed extract was dried with anhydrous sodium sulphate and suitable samples of the supernatant were taken for investigation. (ii) Preparative oxidations. These were performed as above, with proportionally larger amounts of reagents and solvents. Extraction was carried out with four portions of ethylene dichloride in the usual manner.

Various. Melting points were determined on a Kofler stage. Unless otherwise stated, infrared spectra were determined in carbon disulphide, ultraviolet spectra in ethanol and optical rotations in chloroform. Samples for elementary analysis were dried in vacuo $(0.1 \mathrm{~mm}$. $\mathrm{Hg}$ ) at $80^{\circ}$ for 3-6 hr.; the analyses were performed by Weiler and Strauss, Oxford. Zimmermann chromogens were determined according to Corker, Norymberski \& Thow (1962) and aldehydes according to Exley, Ingall, Norymberski \& Woods (1961). Pyridine (AnalaR) was refluxed over potassium hydroxide pellets, distilled and stored over potassium hydroxide. Ethylene dichloride (May and Baker Ltd.) was distilled. All other solvents were of analytical grade.

\section{Oxidations}

For paper-chromatographic analysis of products, samples of 50-100 $\mu \mathrm{g}$. were taken. The $R_{F}$ values are for systems $\mathrm{B}_{3}$ and $\mathbf{E}_{4}$ unless stated otherwise.

(1) $5 \beta$-Pregnane-3 $\alpha, 20 \alpha$-diol. This compound (104 mg.) gave a crude product (103 mg.), m.p. $119-121^{\circ}$. Crystallization from $n$-hexane gave heavy crystals, m.p. 121-122 ${ }^{\circ}$ undepressed on admixture of $5 \beta$-pregnane-3,20-dione. The $R_{F}$ values and infrared spectrum were identical with those of authentic material.

(2) $3 \alpha-H y d r o x y-5 \alpha$-androstan-17-one. This compound (108 mg.) gave a gummy crude product (108 mg.). Paper chromatography revealed (test $c$ ) only one component with mobilities identical with those of $5 \alpha$-androstane-3,17-dione. Crystals were obtained, from ether- $n$-hexane $(2: 1, v / v)$, which had m.p. $129-130^{\circ}$ and were identical with authentic material by mixed m.p. and comparison of infrared spectra.

(3) $5 \beta$-Pregnane- $3 \alpha, 11 \beta, 17 \alpha, 20 \beta$-tetraol. This compound [crude product from the borohydride (tetrahydroborate) reduction of the corresponding 11,20-dione (116 mg.)] yielded an oily crude product (77 $\mathrm{mg}$.). Chromatography on alumina and crystallization of the main fraction $(59 \mathrm{mg}$.) from ether gave pure $5 \beta$-androstane-3,11,17-trione, m.p. $128-130^{\circ}$ undepressed on admixture of the authentic material. Its chromatographic mobilities and its infrared spectrum were identical with those of the authentic material. Paper chromatography of the crude product showed the presence of small amounts of $17 \alpha$-hydroxy- $5 \beta$ pregnane-3,11,20-trione.

(4) $3 \alpha, 17 \alpha$-Dihydroxy-5 $\beta$-pregnane-11,20-dione. This compound $(96 \mathrm{mg}$.) gave a crystalline crude product $(92 \mathrm{mg}$.). Crystallization from acetone-ether $(1: 1, \mathrm{v} / \mathrm{v})$ gave pure $17 \alpha$-hydroxy-5 $\beta$-pregnane-3,11,20-trione, m.p. $197-199^{\circ}$, $[\alpha]_{\mathrm{b}}+33^{\circ}(c \quad 0.92), \nu_{\max } .3700,3550,1720 \mathrm{~cm} .^{-1}$ (in methylene dichloride), $R_{F} 0.24$ (in $\mathrm{B}_{3}$ ) and $0 \cdot 17$ (in $\mathrm{E}_{4}$ ) (Found: C, 72.6; H, 8.6. Calc. for $\mathrm{C}_{21} \mathrm{H}_{30} \mathrm{O}_{4}: \mathrm{C}, 72 \cdot 8 ; \mathrm{H}$, 8.7\%). These properties agree with those reported (Sarett, 1948; Kritchevsky, Garmaise \& Gallagher, 1952; Ercoli \& de Ruggieri, 1955). Paper chromatography of the crude product revealed the presence of a minor component with the mobilities of $5 \beta$-androstane-3,11,17-trione.

(5) Cholesterol. This compound $(120 \mathrm{mg}$.) yielded a semicrystalline crude product (123 mg.). Chromatography on alumina gave cholest-4-ene-3,6-dione (74 mg.), which crystalized from methanol in pale-yellow needles, m.p. 121-122 $[\alpha]_{\mathrm{D}}-43^{\circ}(c 0.95), \lambda_{\max .} 251 \mathrm{~m} \mu(\epsilon 11900)$, in aq.-ethanolic 
$(50 \%, v / v) 0.5 \mathrm{~N}$-sodium hydroxide $\lambda_{\max } 225 \mathrm{~m} \mu(\epsilon 6000)$, $262 \mathrm{~m} \mu(\epsilon 9900)$ and $383 \mathrm{~m} \mu(\epsilon 9200), \nu_{\max } 1700 \mathrm{~cm} .{ }^{-1}, R_{F}$ 0.85 (in $B_{3}$ ) and 0.78 (in $\mathrm{E}_{4}$ ) (Found: $\mathrm{C}, 80.9 ; \mathrm{H}, 10 \cdot 4$. Calc. for $\mathrm{C}_{27} \mathrm{H}_{42} \mathrm{O}_{2}$ : C, $81 \cdot 3 ; \mathrm{H}, 10 \cdot 6 \%$ ). These properties agree well with those reported (Ross, 1946; Fieser, 1953; Amendolla, Rosenkranz \& Sondheimer, 1954; Meyer, 1955). Paper chromatography (in $\mathrm{B}_{3}$ ) of the crude product failed to reveal (tests $a, b$ and $c$ ) any by-products.

(6) 3 $\beta$-Hydroxypregn-5-en-20-one. This compound (115 mg.) gave a crude product (113 mg.) resolved on alumina into three fractions (56, 8 and $2 \mathrm{mg}$. respectively, in the order of elution). Crystallization of the major fraction from methanol gave pure pregn-4-ene-3,6,20-trione, m.p. $192-194^{\circ},[\alpha]_{\mathrm{D}}+16^{\circ}(c, 0.93), \lambda_{\max .} 251 \mathrm{~m} \mu(\epsilon 11900)$, in aq.ethanolic $(50 \%, v / v) 0.5 \mathrm{~N}$-sodium hydroxide $\lambda_{\max } .225 \mathrm{~m} \mu$ (є 5700), $262 \mathrm{~m} \mu(\epsilon 9400)$ and $383 \mathrm{~m} \mu$ (8500), $\nu_{\max } 1720$ and $1700 \mathrm{~cm} .^{-1}, R_{F} 0.56$ (in $\mathrm{B}_{3}$ ) and 0.21 (in $\mathrm{E}_{4}$ ) (Found: $\mathrm{C}$, 76.3; H, 8.9. Calc. for $\mathrm{C}_{21} \mathrm{H}_{28} \mathrm{O}_{3}: \mathrm{C}, 76 \cdot 8 ; \mathrm{H}, 8 \cdot 6 \%$ ). These properties agree with those reported (Ehrenstein, 1939; Moffet, Stafford, Linsk \& Hoehn, 1946; Amendolla et al. 1954; Ellis \& Petrow, 1956).

The second fraction eluted from alumina gave, from acetone- $n$-hexane $(3: 1, v / v)$, crystals, m.p. $176-178^{\circ}$, $\lambda_{\max } 237 \mathrm{~m} \mu \quad(\epsilon 11800), \nu_{\max }$ (in methylene dichloride) $3700,3600,1710$ and $1680 \mathrm{~cm}^{-1}, R_{F} 0.28$ (in $\mathrm{B}_{3}$ ) and 0.22 (in $\mathrm{E}_{4}$ ), identical with $6 \beta$-hydroxyprogesterone by mixed m.p. and comparison of infrared spectra. After $24 \mathrm{hr}$. in aq.-ethanolic $(50 \%, \nabla / v) \quad 0.5 \mathrm{~N}$-sodium hydroxide it had $\lambda_{\mathrm{mpx}} .225 \mathrm{~m} \mu \quad(\epsilon 6100), 261 \mathrm{~m} \mu \quad(\epsilon 9400)$ and $382 \mathrm{~m} \mu$ $(\epsilon 8000)$; 10 min. after dissolution the extinction at $382 \mathrm{~m} \mu$ was $30 \%$ of the last value (see Meyer, 1955). On oxidation with tert.-butyl chromate it gave by paper-chromatographic evidence (in $\mathrm{B}_{\mathrm{3}}$; tests $a$ and $b$ ) pregn-4-ene-3,6,20-trione.

The third fraction from alumina, $6 \alpha$-hydroxyprogesterone, had $\lambda_{\max .} 241 \mathrm{~m} \mu \quad(\epsilon 10600), \nu_{\max }$. (in methylene dichloride) $3700,3600,1710$ and $1670 \mathrm{~cm} .^{-1}, R_{F} 0.17$ (in $B_{3}$ ) and 0.14 (in $E_{4}$ ). After $24 \mathrm{hr}$. in aq.-ethanolic (50\%, $v / v) 0.5 \mathrm{~N}$-sodium hydroxide it had $\lambda_{\max }, 225 \mathrm{~m} \mu(\epsilon 4600)$, $261 \mathrm{~m} \mu(7100)$ and $382 \mathrm{~m} \mu(\epsilon 6000)$; $10 \mathrm{~min}$. after dissolution its extinction at $382 \mathrm{~m} \mu$ was $50 \%$ of the last value (see Meyer, 1955).

(7) Dehydroepiandrosterone. The crude product (102 mg.) from dehydroepiandrosterone (121 mg.) was resolved on alumina into three fractions $(46,15$ and $1 \mathrm{mg}$. respectively, in the order of elution). Crystallization of the main product from acetone-ether $(1: 1, v / v)$ gave pure androst-4ene-3,6,17-trione in prisms, m.p. 223-224 ${ }^{\circ}\left(227-228^{\circ}\right.$ after drying in vacuo $\left.),[\alpha]_{\mathrm{D}}+18^{\circ}(c) 0.97\right)$ and $+36^{\circ}(c 0.86$ in acetone), $\lambda_{\max } 251 \mathrm{~m} \mu(\epsilon 10400)$ and $315 \mathrm{~m} \mu(\epsilon 820)$, in aq.-ethanolic $(50 \%, \mathrm{v} / \mathrm{v}) \quad 0.5 \mathrm{~N}$-sodium hydroxide $\lambda_{\max }$. $225 \mathrm{~m} \mu(\epsilon 6800), 261 \mathrm{~m} \mu(\epsilon 11200)$ and $379 \mathrm{~m} \mu(\epsilon 9700)$, $\nu_{\max } 1750$ and $1700 \mathrm{~cm} .^{-1}, R_{F} 0.41$ (in $\mathrm{B}_{3}$ ) and 0.11 (in $\mathrm{E}_{4}$ ) (Found: C, 75.7; H, 8.0. Calc. for $\mathrm{C}_{19} \mathrm{H}_{24} \mathrm{O}_{3}: \mathrm{C}, 76.0 ; \mathrm{H}$, $8.0 \%$ ). These properties agree with those reported (Butenandt \& Riegel, 1936; Amendolla et al. 1954; Meyer, 1955). Paper chromatography (in $\mathrm{B}_{3}$ ) of the pure compound $(50 \mu \mathrm{g}$.$) revealed a minor polar fraction \left(R_{F} 0 \cdot 07\right)$ in addition to the main fraction $\left(R_{F} \mathbf{0 \cdot 4 1}\right)$. Both fractions were eluted with ethanol and re-run in the same system: the main product again gave the polar fraction in roughly the same yield; the polar fraction gave only one detectable spot with $R_{F} \mathbf{0} \cdot \mathbf{4 1}$.

The second fraction eluted from alumina, $6 \beta$-hydroxyandrost-4-ene-3,17-dione, had $\lambda_{\max .} 238 \mathrm{~m} \mu \quad(\epsilon 10600)$, $\nu_{\max }$ (in methylene dichloride) 3750, 3650, 1740 and $1680 \mathrm{~cm} .^{-1}, R_{F} 0.16$ (in $\mathrm{B}_{3}$ ) and $0.12\left(\right.$ in $\mathrm{E}_{4}$ ). After. $24 \mathrm{hr}$. in aq.-ethanolic $(50 \%, v / v) \quad 0.5 \mathrm{~N}$-sodium hydroxide it had $\lambda_{\operatorname{msx}} 225,260$ and $380 \mathrm{~m} \mu(\epsilon 6200,11500$ and 10000 respectively); after $20 \mathrm{~min}$., the extinction at $380 \mathrm{~m} \mu$ was $40 \%$ of the value given above. Oxidation with the tert.butyl chromate reagent gave androst-4-ene-3,6,17-trione, detected by its mobility in the $\mathrm{B}_{3}$ system and by the alkali test.

The third fraction eluted from alumina, 6 $\alpha$-hydroxyandrost-4-ene-3,17-dione, had $\lambda_{\max .} 241 \mathrm{~m} \mu$ ( $\left.\epsilon 13500\right)$, $\nu_{\max }$. (in methylene dichloride) 3750, 3650, 1740 and $1680 \mathrm{~cm} .^{-1}, R_{F} 0.07$ (in $\mathrm{B}_{3}$ ) and 0.06 (in $\mathrm{E}_{4}$ ). After $24 \mathrm{hr}$. in

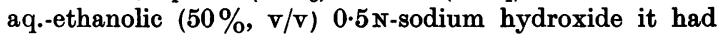
$\lambda_{\text {max. }} 225,260$ and $380 \mathrm{~m} \mu(\epsilon 7300,11600$ and 8800 respectively); after $20 \mathrm{~min}$., the extinction at $380 \mathrm{~m} \mu$ was $60 \%$ of the value given above. Oxidation with the tert.butyl chromate reagent gave androst-4-ene-3,6,17-trione, detected as above.

The rate of formation of androst-4-ene-3,6,17-trione from dehydroepiandrosterone was established by measuring at intervals the extinction at $380 \mathrm{~m} \mu$ of the crude reaction product immediately after its dissolution in aq.-ethanolic alkali; the measurements were repeated after $24 \mathrm{hr}$. (Fig. 1). The crude products obtained after oxidation for $1,4,10$ and $24 \mathrm{hr}$. were submitted to paper chromatography (in $\mathrm{B}_{3}$ ), and the chromatograms, evaluated by tests $(a),(b)$ and $(c)$, showed (i) the main product, androst-4-ene3,6,17-trione $\left(R_{F} 0 \cdot 41\right)$, readily detected by all three tests; (ii) a minor by-product with $R_{F} 0 \cdot 07$, corresponding to $6 \alpha$ hydroxyandrost-4-ene-3,17-dione but giving immediately a full response to the alkali test, diminished only slightly

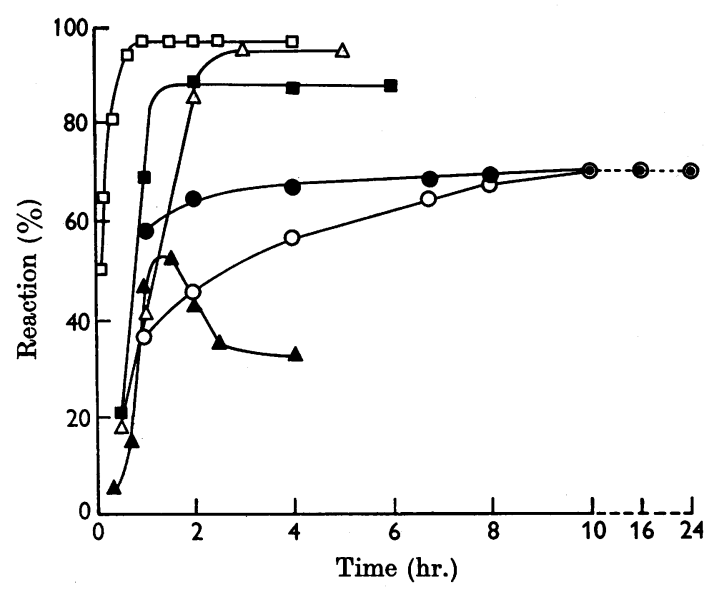

Fig. 1. Rates of oxidation of: $\square$, testosterone at $\mathrm{C}_{(17)}$ (by Zimmermann reaction); $\square$, bisnorchol-4-ene-3 $\beta, 22$-diol at $\mathrm{C}_{(3)}$ (by $E_{240}$ ); $\Delta$, bisnorchol-4-ene-3 $\beta, 22$-diol at $\mathrm{C}_{(22)}$ (by aldehyde assay); $\Delta, 6 \beta$-hydroxyprogesterone at $\mathrm{C}_{(6)}$ (by $E_{380}$ in alkaline solution); $\bigcirc$, dehydroepiandrosterone to androst-4-ene-3,6,17-trione (by $E_{380}$ in alkaline solution); , dehydroepiandrosterone to androst-4-ene-3,6,17-trione and corresponding 6-hydroxy compounds (by $E_{380}$ after $24 \mathrm{hr}$. in alkaline solution). All oxidations were performed at 'room temperature' without any attempt to ensure constant or reproducible conditions. 
with increasing time of oxidation; (iii) a by-product with $R_{F} 0 \cdot 15$, corresponding to that of $6 \beta$-hydroxyandrost-4ene-3,17-dione, abundant after oxidation for $1 \mathrm{hr}$. but hardly detectable after $10 \mathrm{hr}$; (iv) a minor by-product (test $c$ ) with $R_{F} \quad 0.49$ whose yield was not perceptibly affected by the time of oxidation; the infrared spectrum of the crude product obtained after oxidation for $10 \mathrm{hr}$. was indistinguishable from that of pure androst-4-ene-3,6,17trione.

Dehydroepiandrosterone was oxidized $(5 \cdot 2 \mathrm{mg}$.) with chromic anhydride (50 mg.) in pyridine (1.2 ml.) according to Poos et al. (1953), when paper chromatography (in $\mathrm{B}_{3}$ ) showed androst-4-ene-3,6,17-trione (tests $a, b$ and $c$ ) to be the main product and indicated two minor by-products with $R_{F} 0.08$ (tests $a, b$ and $c$ ) and $R_{F}, 0.49$ (test $c$ ) respectively. In alkaline solution the crude product showed absorption at $380 \mathrm{~m} \mu$ corresponding to a $62 \%$ yield of androst-4-ene-3,6,17-trione. The infrared spectrum was identical with that of authentic androst-4-ene-3,6,17-trione.

(8) 6 $\beta$-Hydroxypregn-4-ene-3,20-dione. This compound $(0.66 \mathrm{mg}$.) was oxidized by the general procedure. Paper chromatography of the crude product revealed, by tests $(a)$ and $(b)$, only one component. Its mobilities and its infrared spectrum were identical with those of pregn-4-ene$3,6,20$-trione prepared from $3 \beta$-hydroxypregn-5-en-20-one (see above). The rate of this oxidation is shown in Fig. 1.

(9) Cortisol. This compound $(0.58 \mathrm{mg}$.) gave a crude product whose chromatographic mobilities and infrared spectrum were identical with those of androst-4-ene3,11,17-trione.

(10) Cortisol acetate. This compound (0.6 mg.) gave a crude product whose infrared spectrum (in methylene dichloride) was identical with that of cortisone acetate. However, paper chromatography revealed a minor component with the mobilities of androst-4-ene-3,11,17-trione.

(11) Corticosterone acetate. This compound (0.47 mg.) gave a crude product whose chromatographic mobilities and infrared spectrum were identical with those of authentic 11-dehydrocorticosterone acetate.

(12) Androst-4-ene-3 $\beta, 17 \beta$-diol. This compound (0.48 mg.) gave a crude product whose chromatographic mobilities and infrared spectrum were identical with those of authentic androst-4-ene-3,17-dione.

(13) Testosterone. Various amounts (4-30 $\mu \mathrm{g}$.) of this compound were oxidized by the general procedure and suitable portions of the product assayed by test (c). A linear relation was obtained between the amount of testosterone and that of its chromogenic product. The rate of oxidation (Fig. 1) was determined by the same analytical means. After $2 \mathrm{hr}$. or more of oxidation androst-4-ene-3,17dione was obtained in $80-90 \%$ yield when, as in the above experiments, the usual wash with sodium disulphite (see general procedure) was omitted. When this was rectified, the product was obtained in theoretical yield. The crude product ( $1.4 \mathrm{mg}$.) remaining from the above oxidations was homogeneous and was identical with androst-4-ene-3,17dione by paper chromatography. At $150-170^{\circ}$ in vacuo $(0.1 \mathrm{~mm}$. $\mathrm{Hg})$ it gave a crystalline sublimate (m.p. 157$\left.158^{\circ}\right)$ whose infrared spectrum was identical with that of authentic material.

(14) Bisnorchol-4-ene-3 $\beta, 22-d i o l$. Portions (350 $\mu$ g. each) of this compound (m.p. $210^{\circ}$; prepared by tetrahydroborate reduction of 3-oxobisnorchol-4-en-22-al) were oxidized for times varying between $5 \mathrm{~min}$. and $4 \mathrm{hr}$. Suitable samples were taken for the determination of extinction at $241 \mathrm{~m} \mu$ and of aldehydes (Fig. 1).

(15) Oestradiol methyl ether. This compound (370 $\mu \mathrm{g}$.$) gave$ a crude product which was homogeneous and identical with oestrone methyl ether by paper chromatography (in $B_{3}$; antimony trichloride test); $\lambda_{\max .} 278$ and $287 \mathrm{~m} \mu$.

(16) Oestradiol. Oestradiol $(0 \cdot 4 \mathrm{mg}$.) gave a crude product which showed no specific absorption in the ultraviolet.

(17) $5 \beta$-Pregnane-3 $\beta, 16 \beta, 20 \alpha$-triol. The crude product obtained from this compound $(0.8 \mathrm{mg}$.) was submitted to paper chromatography but no fractions responding to test (c) could be detected. Its infrared spectrum showed only weak $\mathrm{C}-\mathrm{H}\left(3000 \mathrm{~cm} .^{-1}\right)$ and $\mathrm{C}=\mathrm{O}\left(1730 \mathrm{~cm} .^{-1}\right)$ absorption, indicating loss of material presumably due to the formation of acidic products and their removal in the work-up.

(18)-(20) Attempted oxidations. Dehydroepiandrosterone acetate (0.2 mg.), $5 \alpha$-androst-3-en-17-one (1.0 mg.) and 21 acetoxypregna-4,17-dien-3-one $(1 \cdot 1 \mathrm{mg}$.) were treated with tert.-butyl chromate by the general procedure. In each case paper chromatography of the material isolated from the reaction mixture detected only the starting material.

\section{Properties of $\Delta^{4}$-3,6-diones in alkaline solution}

Visual inspection of the yellow alkaline solutions of $\Delta^{4}$-3,6-diones at approximately $360 \mathrm{~m} \mu$ showed an orange fluorescence clearly perceptible at a concentration of $0.5 \mu \mathrm{g} . / \mathrm{ml}$. turning gradually to bright yellow with increasing concentration. Neither the concentration of alkali $(0 \cdot 2-5 \mathrm{~N})$ nor the nature of the solvent (water or ethanol or mixtures of the two) seemed to influence the intensity of fluorescence, but heating of the alkaline solutions at $100^{\circ}$ diminished the intensity of fluorescence. The $\Delta^{4}-3,6$-diones were extracted from their aq.-alkaline solutions by chloroform and by benzene but not in all instances by ether (see below). Absorption spectra in alkaline solution were reported above.

\section{Partition of $\Delta^{4}$-3,6-diones between alkali and ether}

Samples (30-100 $\mu$ g.) of cholest-4-ene-3,6-dione, pregn4-ene-3,6,20-trione and androst-4-ene-3,6,17-trione were dissolved in ether $(3.0 \mathrm{ml}$.) and the solutions shaken with equal volumes of $0.5 \mathrm{~N}-, \mathrm{N}-, 2 \mathrm{~N}-$ and, in one instance, $5 \mathrm{~N}$ sodium hydroxide. Samples of the organic phases were evaporated to dryness and the residues dissolved in aq.ethanolic $(1: 1, \mathrm{v} / \mathrm{v}) 0.5 \mathrm{~N}$-sodium hydroxide; samples of the aqueous phases were made $0.5 \mathrm{~N}$ with respect to sodium hydroxide and $50 \%(\mathrm{v} / \mathrm{v})$ with respect to ethanol. The extinctions at $380 \mathrm{~m} \mu$ were then determined. The respective percentages in ether (and in alkali) were: cholest. 4-ene-3,6-dione: $100(0), 94(6), 100(0)$; pregn-4-ene-3,6,20trione: $85(15), 73(27), 98(0)$; androst-4-ene-3,6,17-trione: $8(88), 8(91), 10(88)$ and $42(52)$, the last two values referring to $5 \mathrm{~N}$-sodium hydroxide.

\section{Separation of androst-4-ere-3,6,17-trione from pregn- 4-ene-3,6,20-trione ard cholest-4-ene-3,6-dione}

A mixture of these three compounds $(28,20$ and $18 \mu \mathrm{g}$. respectively) was dissolved in ether $(3 \mathrm{ml}$.$) , the solution$ extracted with $2 \mathrm{~N}$-sodium hydroxide $(3 \mathrm{ml}$., twice) and the extract washed with ether $(2 \mathrm{ml}$.). The extinction at $380 \mathrm{~m} \mu$ of the alkaline extract corresponded to $105 \%$ of androst-4-ene-3,6,17-trione; acidification followed by 
extraction with ether and paper chromatography (in $B_{3}$ ) showed that this compound was the sole constituent of the alkaline extract. By the same criteria, the ethereal extract contained only cholest-4-ene-3,6-dione and pregn-4-ene3,6,20-trione.

\section{RESULTS}

The results of oxidations with tert.-butyl chromate are best considered under the following headings.

Secondary alcohols. In the absence of vicinal groups participating in the reaction (see below), compounds of this class [compounds (1), (2), (11), (12) and (13), listed under 'Oxidations'] gave the corresponding ketones in high yield. Testosterone was determined by its conversion into androst-4ene-3,17-dione and measurement of the latter in the Zimmermann reaction. The method was used to establish the rate of the oxidation (Fig. 1). Allylic alcohols [compounds (8), (12) and (14)] gave $\alpha, \beta$ unsaturated ketones, and, as with oxidation with manganese dioxide (Amendolla et al. 1954), the reaction proceeded faster with $\Delta^{4}-3 \beta$-ols than with $\Delta^{4}$-6 $\beta$-ols (Fig. 1).

Primary alcohol. Oxidation of a 22-ol [compound (14)] gave the 22-al with a maximal yield of $52 \%$ attained after $1.5 \mathrm{hr}$. which then declined (Fig. 1), presumably owing to further oxidation.

$\alpha$-Glycols and $\alpha$-ketols. 5 $\beta$-Pregnane-3 $\alpha, 11 \beta, 17 \alpha$, $20 \beta$-tetraol [compounds (3)] gave $5 \beta$-androstane$3,11,17$-trione as the main product and $17 \alpha$ hydroxy-5 $\beta$-pregnane-3,11,20-trione as a minor by-product. $3 \alpha, 17 \alpha$-Dihydroxy-5 $\beta$-pregnane-11,20dione [compound (4)] gave the same products in inverse ratio. These findings establish that oxidation of 17,20-ketols proceeds very slowly and that the fission of glycols proceeds much more rapidly than oxidation of secondary alcohols. Cortisol [compound (9)] gave androst-4-ene-3,11,17-trione as the sole product, whereas cortisol acetate [compound (10)] gave cortisone acetate as the main product and androst-4-ene-3,11,17-trione as a minor by-product; clearly, the initial attack in the former reaction consisted in the fission of the $\mathrm{C}_{(20)}-\mathrm{C}_{(21)}$ bond.

$\beta$-Glycol. A 16,20-glycol [compound (17)] gave no identifiable product. It is likely that the main product was an acid and that it escaped detection.

Phenols. No product was identified from the oxidation of oestradiol [compound (16)]; spectroscopic evidence indicated destruction of the aromatic ring. Oxidation of oestradiol methyl ether [compound (15)] gave oestrone methyl ether as the sole product.

Inert groupings. By implication it follows from the above that saturated ketones, $\alpha, \beta$-unsaturated ketones, and the benzene nucleus (but not phenols) are completely resistant to the action of tert.-butyl chromate in pyridine: so are acetoxy groups [compounds (11), (18) and (19)] and ethylenic bonds [compounds (18), (19) and (20)], except for the homoallylic system of $\Delta^{5}-3 \beta$-ols (see below).
$\mathrm{I} a: \mathrm{X}=\mathrm{C}_{8} \mathrm{H}_{17}, \mathrm{Y}=\mathrm{H}$

$\mathrm{I} b: \mathrm{X}=\mathrm{CH}_{3} \cdot \mathrm{CO}, \mathrm{Y}=\mathrm{H}$ $\mathrm{I} c: \mathrm{XY}=\mathrm{O}$

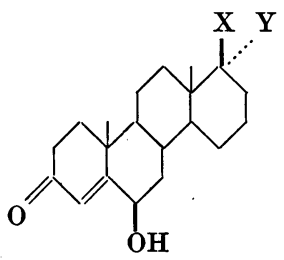

III $a: \mathrm{X}=\mathrm{C}_{8} \mathrm{H}_{17}, \mathrm{Y}=\mathrm{H}$

III $b: \mathrm{X}=\mathrm{CH}_{3} \cdot \mathrm{CO}, \mathrm{Y}=\mathrm{H}$

III $c: \mathrm{XY}=\mathrm{O}$

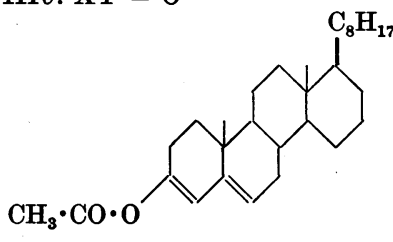

V

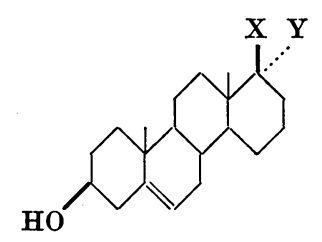

II $a: \mathrm{X}=\mathrm{C}_{8} \mathrm{H}_{17}, \mathrm{Y}=\mathrm{H}$ II $b: \mathrm{X}=\mathrm{CH}_{3} \cdot \mathrm{CO}, \mathrm{Y}=\mathrm{H}$ II $c: \mathrm{XY}=\mathrm{O}$

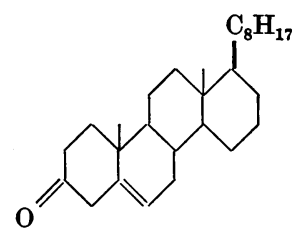

IV

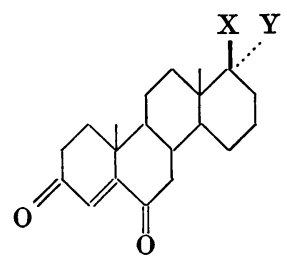

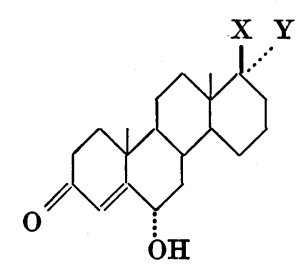

VI $b: \mathrm{X}=\mathrm{CH}_{3} \cdot \mathrm{CO}, \mathrm{Y}=\mathrm{H}$
VIc $: \mathrm{XY}=\mathrm{O}$
$\Delta^{5}$-3 $\beta$-ols. Mauthner \& Suida (1896) oxidized cholesterol ( $\mathrm{I} a)$ with chromic acid and isolated a product recognized by Windaus (1906) as cholest4-ene-3,6-dione (II $a$ ). Fieser (1953) greatly improved the yield (up to $42 \%$ ) of this product by performing the oxidation with sodium dichromate in a mixture of acetic acid and benzene under carefully controlled conditions. $H e$ found that with only 2-3 oxygen equivalents of the oxidant $6 \beta$ hydroxycholest-4-en-3-one (III $a$ ) and cholest-5en-3-one (IV) were obtained in 17 and $20 \%$ yield respectively, and that, under identical conditions, the latter compound as well as the enol acetate of cholest-4-en-3-one (V) gave cholest-4-ene-3,6-dione (II $a$ ) in approximately $20 \%$ yield. He concluded that the conversion of cholesterol (I $a$ ) into the enedione (II $a$ ) proceeds via the 5-en-3-one (IV) and, possibly by 1,4-addition to its enol form, the 6 $\beta$-hydroxy-4-en-3-one (III $a$ ). Oppenauer \& Oberrauch (1949) reported that the oxidation of cholesterol ( $\mathrm{I} a$ ) with tert.-butyl chromate in a mixture of 2-methylpropan-2-ol and an inert nonpolar solvent gave unidentified acidic products. We find that, in the presence of pyridine, the latter 
reagent converts cholesterol into the chromatographically pure enedione (II $a$ ) in $58 \%$ yield. Oxidation of pregnenolone (Ib) gave pregn-4-ene$3,6,20$-trione (II $b)$ in $47 \%$ yield and two more polar by-products in 7 and $2 \%$ yield respectively. The major by product had $\lambda_{\max } 237 \mathrm{~m} \mu(\epsilon 11300)$ and was identified as $6 \beta$-hydroxypregn-4-ene-3,20dione (III $b$ ) by comparison with authentic material. The minor by-product had $\lambda_{\max .} 241 \mathrm{~m} \mu(\epsilon 10600)$, showed in the infrared two hydroxyl bands (3700 and $\left.3600 \mathrm{~cm} \cdot{ }^{-1}\right)$ and two carbonyl bands (1710 and $\left.1670 \mathrm{~cm}^{-1}\right)$, and was oxidized by the tert.-butyl chromate reagent to pregn-4-ene-3,6,20-trione (IIb). These findings, the compound's $R_{M}$ value (Table 1) and its spectroscopic properties in alkaline solution (see below) permit its formulation as $6 \alpha$-hydroxypregn-4-ene-3,20-dione (VIb).

Dehydroepiandrosterone (Ic) gave androst-4ene-3,6,17-trione (II $c$ ) in $36 \%$ yield and two more polar by-products in 12 and $1 \%$ yield respectively. Both by-products gave with tert.-butyl chromate the 3,6,17-trione (IIc) and both exhibited infrared spectra with two hydroxyl bands (3700 and 3600 cm. ${ }^{-1}$ ) and two carbonyl bands (1740 and 1680 cm. ${ }^{-1}$ ). The less polar and more abundant byproduct had $\lambda_{\max }, 238 \mathrm{~m} \mu(\epsilon 10600)$ and the more polar $\lambda_{\max } 241 \mathrm{~m} \mu(\epsilon 13500)$. Further indication of structure is given by their $R_{M}$ values (Table 1 ) and their spectroscopic properties in alkaline solution (see below), and hence we assign the structure of 6 $\beta$-hydroxyandrost-4-ene-3,17-dione (III $c$ ) to the former and that of its 6-epimer (VIc) to the latter.

Paper chromatography [in system $\mathrm{B}_{3}$ (Bush, 1952)] of the (by many criteria, see Experimental section) pure androst-4-ene-3,6,17-trione (IIc) invariably showed the presence of a more polar substance which gave compound (IIc) when eluted from the paper. We conclude that, in the chromatographic system employed, androst-4-ene3,6,17-trione (IIc) is in equilibrium with its enol form. This interpretation is consistent with the unusually strong absorption of compound (II $c$ ) at $315 \mathrm{~m} \mu(\epsilon \mathrm{820})$. Similarly, pure pregn-4-ene-3,6,20trione (IIb) gave two chromatographic fractions; analogy suggests that the minor more polar fraction be formulated as the enol of (IIb). By the same means, no evidence was found for the presence of the enol of cholest-4-ene-3,6-dione (II $a$ ).

In alkaline solution, the 4-ene-3,6-diones (II $a$, $b, c)$ exhibited spectra with peak absorptions at about 225, 261 and $380 \mathrm{~m} \mu$ (Meyer, 1955) and strong yellow fluorescence in ultraviolet light. On paper treated with alkali, they instantly gave fluorescing yellow spots in ultraviolet light. Characteristically (Meyer, 1955), the corresponding 6-hydroxy compounds (III $b, c ; \mathrm{VI} b, c$ ) gave, in time, identical spectra, the $6 \alpha$-hydroxy compounds more quickly than their epimers. The $6 \alpha$-hydroxy compounds (VI $b, c)$ responded initially to the alkali test on paper more weakly than the ketones but the intensity of colour and fluorescence rapidly increased; their epimers (III $b, c$ ) responded more weakly and slowly.

The light-absorption of 4-ene-3,6-diones in alkaline solution obeys Beer's law and hence provides a simple means for their determination and, indirectly, of 5-en-3 $\beta$-ols. The method was used to determine the rate of formation of androst4-ene-3,6,17-trione (II c) from dehydroepiandrosterone (Ic) by performing the measurement immediately after the dissolution of the crude reaction product in alkali. The sum total of this compound and of the corresponding 6-hydroxy compounds (II $c$ and VIc) was determined by repeating the measurement after $24 \mathrm{hr}$.: Fig. 1 shows that considerable amounts of the 6-hydroxy compounds were present after a short reaction time but these could not be detected after oxidation for $10 \mathrm{hr}$., when a $70 \%$ yield of the end-product was attained. Paper-chromatographic analysis of the reaction products confirmed that the yield of $6 \beta$-hydroxy-

Table 1. The $R_{M}$ values of 6-oxygenated 4-en-3-ones

Experimental details are given in the text. $R_{M}=\log \left(\frac{1}{R_{F}}-1\right)$.

Solvent system

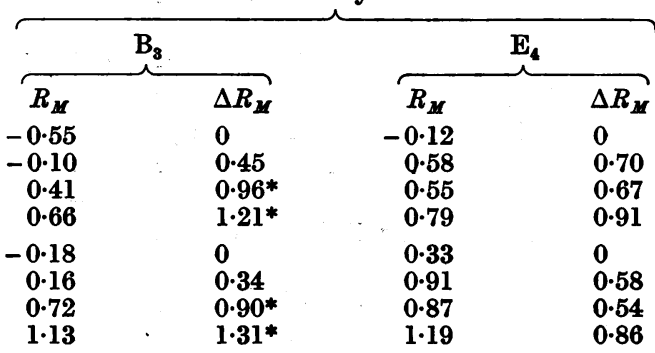

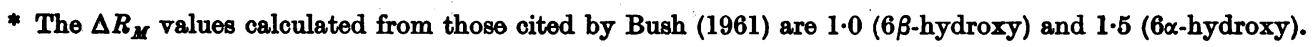


androstenedione (II c) rapidly declined with time; the fraction corresponding to $6 \alpha$-hydroxyandrostenedione (VIc) was only very slightly affected by the time of oxidation. The latter finding is readily explained by the fact that the compound has the same mobility as the enol of the end-product (IIc). In the above experiments a much larger excess of the oxidant was used than in the corresponding preparative experiment, and this is likely to account for the divergence of results.

In contrast with cholest-4-ene-3,6-dione (II $a$ ) (Windaus, 1906) and pregn-4-ene-3,6,20-trione (II $b$ ), androst-4-ene-3,6,17-trione (II $c$ ) was readily extracted with dilute aqueous alkali from its ethereal solution.

\section{DISCUSSION}

Hershberg, Wolfe \& Fieser (1941) determined $\Delta^{5}-3 \beta$-hydroxy steroids by submitting them to the Oppenauer reaction and polarographic measurement of the formed $\Delta^{4}$-3-oxo compounds. Wilson \& Fairbanks (1955) used the oxidation with chromic anhydride in acetic acid followed by the Zimmermann reaction to determine compounds of the androstane series with an oxygen function at position 17 and compounds of the pregnane series with vicinal oxygen functions at positions 17 and 20. Whatever the nature of the compounds under investigation and whichever means are used for the detection of their oxidation products, the former method cannot be applied to alkali-sensitive compounds nor the latter to many unsaturated compounds. Oxidation with tert.-butyl chromate in the presence of pyridine does not suffer from these shortcomings and is therefore likely to find more general application in the analysis of steroids. An attractive analytical application of this reagent is conversion of $\Delta^{5}$-3-ols into $\Delta^{4}-3,6$-diones because of the highly characteristic spectroscopic properties of the products. In the special application to the determination of dehydroepiandrosterone advantage may be taken of the ease with which its oxidation product can be separated by extraction with alkali. The strong fluorescence exhibited by $\Delta^{4}-3,6$-diones in alkaline solution or on paper treated with alkali holds promise for the development of a highly sensitive method for their determination and hence of their precursors.

The course of oxidation of bisnorchol-4-ene3 $\beta, 22$-diol suggests that primary alcohols, aldehydes and compounds with vicinal oxygen functions other than ditertiary glycols, 17,20-glycols and 17,20-ketols are convertible into carboxylic acids.

For preparative purposes tert.-butyl chromate in the presence of pyridine is a convenient reagent for small-scale oxidations. It is likely that, under appropriate conditions, it will effect the preferential oxidation of glycols and reactive hydroxyls.
However, the present findings do not suggest that in preparative work the reagent offers any significant advantage over chromic anhydride in pyridine.

\section{SUMMARY}

1. Twenty steroids were oxidized with tert.butyl chromate in the presence of pyridine and the reaction products characterized in most instances. Reaction rates were determined in a few instances.

2. Secondary alcohols gave corresponding ketones, 17-hydroxy corticosteroids gave 17-oxo steroids and, in contrast with the original reagent of Oppenauer \& Oberrauch (1949), $\Delta^{5}-3 \beta$-hydroxy steroids gave $\Delta^{4}-3,6$-diones in high yield.

3. The analytical utility of the reagent was demonstrated by applying it to the determination of 17-hydroxyandrostanes and of $\Delta^{5}-3 \beta$-hydroxy steroids.

We are indebted to Professor W. Klyne for making available to us compounds from the M.R.C. Steroid Reference Collection.

\section{REFERENCES}

Amendolla, C., Rosenkranz, G. \& Sondheimer, F. (1954). J. chem. Soc. p. 1226.

Appleby, J. I. \& Norymberski, J. K. (1955). Biochem. J. $60,460$.

Bush, I. E. (1952). Biochem. J. 50, 370.

Bush, I. E. (1961). The Chromatography of Steroids, p. 385. London: Pergamon Press.

Butenandt, A. \& Riegel, B. (1936). Chem. Ber. 69, 1163.

Corker, C., Norymberski, J. K. \& Thow, R. (1962). Biochem. J. 83, 583.

Eberlein, W. R. \& Bongiovanni, A. M. (1955). Arch. Biochem. Biophys. 59, 90.

Ehrenstein, M. (1939). J. org. Chem. 4, 506.

Ellis, B. \& Petrow, V. (1956). J. chem. Soc. p. 4417.

Ercoli, A. \& de Ruggieri, P. (1955). Gazz.chim. ital. 85, 1304.

Exley, D., Ingall, S. C., Norymberski, J. K. \& Woods, G. F. (1961). Biochem. J. 81, 428.

Fieser, L. F. (1953). J. Amer. chem. Soc. 75, 4377, 4386.

Fieser, L. F. \& Fieser, M. (1959). Steroids, p. 223. New York: Reinhold Publishing Corp.

Hershberg, E. B., Wolfe, J. K. \& Fieser, L. F. (1941). J. biol. Chem. 140, 215.

Kritchevsky, T. H., Garmaise, D. L. \& Gallagher, T. F. (1952). J. Amer. chem. Soc. 74, 483.

Mauthner, J. \& Suida, W. (1896). Mh. Chem. 17, 579.

Meyer, A. S. (1955). J. org. Chem. 20, 1240.

Moffet, R. B., Stafford, J. E., Linsk, J. \& Hoehn, W. M. (1946). J. Amer. chem. Soc. 68, 1857.

Oppenauer, R. V. \& Oberrauch, H. (1949). An. Asoc. quím. argent. 37, 246.

Poos, G. I., Arth, G. E., Beyler, R. E. \& Sarett, L. H. (1953). J. Amer. chem. Soc. 75, 422.

Ross, N. C. J. (1946). J. chem. Soc. p. 737.

Sarett, L. H. (1948). J. Amer. chem. Soc. 70, 1454.

Wilson, H. \& Fairbanks, R. (1955). Arch. Biochem. Biophys. 54, 440.

Windaus, A. (1906). Ber. dtsch. chem. Ges. 39, 2249. 